\title{
Medical expenditure for patients with hemophilia in urban China: data from medical insurance information system from 2013 to 2015
}

Guang-wen Gong ${ }^{1}$, Ying-chun Chen ${ }^{1}$, Peng-qian Fang ${ }^{1 *}$ and Rui Min²

\begin{abstract}
Background: Hemophilia, a high-cost disease, is the only rare disease covered by basic medical insurance in all province of China. However, very few studies have estimated the medical expenditure of patients with this rare disease Therefore, this study is aimed at evaluating the medical expenditure of patients with hemophilia and identifying its determinants.
\end{abstract}

Methods: The study population included 450 patients with hemophilia who were extracted from the national insurance database between 2014 and 2016. An independent-sample Kolmogorov-Smirnov test was performed to compare the medical expenditure of patients with hemophilia covered under urban employee basic medical insurance (UEBMI) and urban residence basic medical insurance (URBMI). Quantile regression analysis was conducted to explore the factors that affect the medical expenditure of patients with hemophilia.

Results: The total annual medical expenditure of patients with hemophilia in 2013, 2014, and 2015 had median of $¥ 7167$ (US\$ 1156), $¥ 3522$ (US\$ 577), and $¥ 4197$ (US\$ 677), respectively. The median medical expenditures of patients with hemophilia covered by UEBMI were $¥ 10,991$ (US\$ 1773), $¥ 2301$ (US\$ 377) and $¥ 8074$ (US\$ 1302), those of patients covered by URBMI were $¥ 4000$ (US\$ 645), $¥ 5717$ (US\$ 937) and $¥ 3141$ (US\$ 507) from 2013 to 2015. The differences in the medical expenditure of patients with hemophilia between UEBMI and URBMI from 2013 to 2015 were statistically significant. The number of admissions and the number of hospital days were statistically significant and positive for all quantiles. The types of medical service were statistically significant and negative for 50th quantile, and the reimbursement ratio was statistically significant and positive for 50th and 75th quantiles. $(p<0.05)$.

Conclusion: The medical expenditure of patients with hemophilia was lower than that of patients with other common rare diseases that were not included in the scope of basic medical insurance reimbursement. It was also observed that the medical expenditure was mainly influenced by the severity of disease, and partly affected by the reimbursement rate.

Keywords: Medical expenditure, Hemophilia, China, Urban employee basic medical insurance, Urban residence basic medical insurance

\footnotetext{
* Correspondence: pfang@mails.timu.edu.cn; ruimin0801@163.com

'School of Medicine and Health Management, Tongji Medical College, Huazhong University of Science and Technology, Wuhan, China

${ }^{2}$ School of Public Health, Tongji Medical College, Huazhong University of Science and Technology, Wuhan, China
}

C C The Author(s). 2020 Open Access This article is licensed under a Creative Commons Attribution 4.0 International License, which permits use, sharing, adaptation, distribution and reproduction in any medium or format, as long as you give appropriate credit to the original author(s) and the source, provide a link to the Creative Commons licence, and indicate if changes were made. The images or other third party material in this article are included in the article's Creative Commons licence, unless indicated otherwise in a credit line to the material. If material is not included in the article's Creative Commons licence and your intended use is not permitted by statutory regulation or exceeds the permitted use, you will need to obtain permission directly from the copyright holder. To view a copy of this licence, visit http://creativecommons.org/licenses/by/4.0/. The Creative Commons Public Domain Dedication waiver (http://creativecommons.org/publicdomain/zero/1.0/) applies to the data made available in this article, unless otherwise stated in a credit line to the data. 


\section{Background}

Hemophilia is a hereditary bleeding disorder that results from the lack or deficiency of clotting factors VIII or IX. The disease is characterized by the spontaneous bleeding of the joints, muscles, viscera and deep tissues and difficulty in stopping the bleeding. It usually requires lifelong treatment and results in a considerable social and economic burden $[1,2]$.

Although China has established a national hemophilia registration system, the registration rate of patients with hemophilia is extremely low, and the prevalence of hemophilia in mainland China remains unclear [3]. It is estimated that in the worldwide population, approximately 400,000 individuals have hemophilia; and the total number of patients with hemophilia in China is $109,426[4,5]$. In a meta-analysis involving existing data, the overall weighted prevalence of hemophilia is 3.6 per 100,000 individuals, and the prevalence among males is 5.5 per 100,000 individuals in mainland China [6]. Hemophilia is a severe health issue in China because it is associated with high treatment cost. According to a research on the treatment cost of hemophilia in Guangdong Province, $12.1 \%$ of treatment cost was more than $¥ 240,000$ (US\$ 34,782) in 2008, $6.1 \%$ treatment cost was between $¥ 120,000$ (US\$ 17,391) and $¥ 240,000,15.2 \%$ of treatment cost was between $¥ 60$, 000 (US\$ 8695) and $¥ 120,000$, and $66.6 \%$ of treatment cost was less than $¥ 60,000$ in 2008 . The quality of life of children with hemophilia is significantly lower than that of healthy children; moreover, their treatment cost is nearly five times higher than that of a healthy family, more than half of families with hemophilia cannot completely afford the therapy in China [7-9]. In 2012, the Chinese Ministry of Health announced that hemophilia is a high-cost disease that should be prioritized to ease their economic burden. Health insurance is an effective way to share the economic risk of diseases. The Chinese government has established a basic medical insurance system and currently it. The current basic medical insurance in China comprises of three main insurance schemes: urban employee basic medical insurance (UEBMI), new rural cooperative medical system (NRCMS), and urban residence basic medical insurance (URBMI). The UEBMI, which was initiated in 1998, covers urban employees and retired employees; the URBMI, established in 2003, covers urban residents, including children, students, elderly people without previous employment, and unemployed people; and the NRCMS, launched in 2007, covers rural residents. The coverage by basic medical insurance is nearly universal, that is, it has exceeded $95 \%$ of the population since 2011 [10]. The financing source of UEBMI comes from employers ( $6 \%$ of total wages) and employees ( $2 \%$ of their wages). The UEBMI and the NRCMS are financed mainly by the government, with minimal individual premium contributions. The UEBMI and URBMI are administered by the Ministry of Human Resources and Social Security, whereas the NRCMS is administered by the Health and Family Planning Commission and run all three are by the local government. According to the local development, each local government sets the local minimum deduction of three insurance schemes, reimbursement cap and an individual's share of medical costs, with the principle of keeping expenditure within income. This is critical as the differences in economic development and health insurance design can result in the disparity of insurance benefit packages [11-16].

The Chinese government has also designed the National Reimbursement Drug List (NRDL), which is divided into class A and class B. All drugs in NRDL were purchased by public bidding. Class A drug were 100\% reimbursed by all the three insurance schemes, but class B were partially reimbursed by three insurance schemes (10-90\%) [17]. Drugs for hemophilia are included in the NRDL, which were reimbursed by the basic medical insurance of each province. According to the National Reimbursement Drug Lis (2004 edition), the freeze-dried human coagulation factor VIII was identified as a class A drug [18]. In the 2009 edition, gene recombinant coagulation factor VIII was identified as a class B drug [19]. In the 2017 edition, human clotting factor VIII was identified as a class A drug, whereas human recombinant coagulation factor IX, a class B drug [20,21]. Drugs for hemophilia are included in the NRDL, which were reimbursed by the basic medical insurance of each province. Thus, hemophilia is the only rare disease that is covered by basic medical insurance in each province in China.

Basic medical insurance focuses on the diseases with a large number of patients, and provides little coverage of rare diseases. This may lead to patients with rare diseases experience high financial burden for patients with rare diseases. Although hemophilia is the only rare disease covered by basic medical insurance, the disparities in insurance benefit packages of basic medical insurance in each province lead to the disparities of medical expenditure for patients with hemophilia. Few studies have explored the disparities in the insurance benefit packages of basic medical insurance affecting the medical expenditure of patients in China. This study aimed to evaluate the medical expenditure of patients with hemophilia, and identify its determinants in mainland China.

\section{Methods}

\section{Data source}

The data used in this study were derived from the national insurance database which is operated by China Healthcare Insurance Research Association (CHIRA). CHIRA extracted data from the medical insurance management system covering the whole country by retrospective sampling method. Sample cities were selected 
by stratified sampling, the sample size is $5 \%$ of the total number of participants of sample cities, and the case was selected by sampling space. The data from 2014 to2016 contain information about disease diagnosis and medical expenditure of patients covered by UEBMI and URBMI from 2013 to 2015. All patients diagnosed with hemophilia and recorded in the database were selected $(155,148$, and 147 patients with hemophilia in 2013, 2014, and 2015, respectively).

\section{Indicators definitions}

For the purpose of this study, medical expenditure was defined as the total direct costs of seeking healthcare services for a patient with hemophilia, which was the sum of treatment cost of each visit in a year. Indirect costs, such as the costs of transportation and special diets and wages lost due to illness, were not considered in this study. Furthermore, medical expenditure was categorized into two components-expenses within and beyond the reimbursement coverage of basic health insurance in China. Expenses beyond the reimbursement coverage of basic health insurance paid by a person is referred to as the out-of-pocket costs. The proportion of medical expenses within the reimbursement coverage of basic health insurance accounted for the medical expenditure is defined as the reimbursement rate (RR) of basic medical insurance. The insurance benefit packages were represented by RR in this study:

$\mathrm{RR}=$ total expenditure reimbursed by basic medical insurance $/$ total medical expenditure $\times 100 \%$

\section{Statistical analysis}

Statistical analysis was performed using SPSS 24.0 for Windows (IBM Corp., Armonk, NY, USA) and STATA/ SE 15. Descriptive analysis and independent-sample Kolmogorov-Smirnov test were performed by SPSS 24.0. The median and interquartile ranges of the medical expenditures of patients with hemophilia were calculated via descriptive analysis. An independent-sample Kolmogorov-Smirnov test was carried out to compare medical expenditure of patients with hemophilia covered by the two types of health insurance schemes. Quantile regression analysis was performed with STATA/SE 15 to explore the factors that affect medical expenditure of patients with hemophilia. Statistical significance was considered at $p<0.05$.

\section{Results}

\section{Descriptive analysis}

Table 1 presents the medical information of patients with hemophilia. The treatment costs of 450 patients with hemophilia from 2013 to 2015 were obtained. Patients with hemophilia were mainly male, which accounted for $89.33 \%$
Table 1 Medical expenses and reimburse ration distribution of patients with haemophilia

\begin{tabular}{lllll}
\hline \multicolumn{1}{c}{ Indicator } & Median & IQR & Non-parametric Test \\
\hline outpatient & medicalexpensest & & & $P=0.000$ \\
& UEBMI & 799.56 & 813.60 & \\
& URBMI & 43.48 & 552.22 & \\
& reimburse ratio,\% & & & $P=0.002$ \\
& UEBMI & 80.00 & 100.00 & \\
& URBMI & 70.00 & 57.13 & \\
inpatient & medicalexpensest & & & $P=0.000$ \\
& UEBMI & 5995.80 & 5689.68 & \\
& URBMI & 3194.93 & 4832.23 & \\
& reimburse ratio,\% & & & $P=0.000$ \\
& UEBMI & 85.67 & 19.20 & \\
URBMI & 63.07 & 30.02 & \\
\hline
\end{tabular}

of the participants. Among the total participants, 52.10\% were covered by UEBMI and, $47.90 \%$ were covered by URBMI. During the study year, $50 \%$ of the patients used the out-patient service, $42.67 \%$ used the in-patient service only, and $7.33 \%$ used both out-patient and in-patient services. It was also found that $22 \%$ RR was less than $30,23.33 \%$ RR was between 30 and $60 \%, 47.56 \%$ RR was between 60 and $90 \%$, and $17.11 \%$ RR was higher than $90 \%$.

Table 2 presents the average annual medical expenditure of patients with hemophilia. The total annual medical expenditures of patients with hemophilia in 2013, 2014, and 2015 had median of $¥ 7167$ (US\$ 1156), $¥ 3522$ (US\$ 577), and $¥ 4197$ (US\$ 677), respectively. The medical expenditures of patients with hemophilia covered by UEBMI had median of $¥ 10,991$ (US\$ 1773), ¥2301 (US\$ 377 ) and $¥ 8074$ (US\$ 1302). By comparison, the medical expenditures of patients with hemophilia $¥ 4000$ (US\$ 645), $¥ 5717$ (US\$ 937) and ¥3141 (US\$ 507) from 2013 to 2015. The differences in medical expenditure of the patients with hemophilia between UEBMI and URBMI from 2013 to 2015 were statistically significant.

\section{Quantile regression}

Table 3 presents quantile regression of medical expenditure. It was noted that age of the participants was not statistically significant for all quantiles. The types of medical service were statistically significant and positive for 50th and 95th quantiles. RR was statistically significant and positive for 50th and 75th quantiles. The number of admissions and the number of hospital days were statistic significant and positive for all quantiles (Table 3, $p<0.05)$.

\section{Discussion}

Medical expenditure, which is not only relate related to the severity of diseases but also affected by technological 
Table 2 The generalised estimating equation analysis of medical expenses

\begin{tabular}{|c|c|c|c|c|c|c|c|}
\hline \multirow[t]{2}{*}{ Parameter } & \multirow[t]{2}{*}{ B } & \multirow[t]{2}{*}{ Std.Error } & \multicolumn{2}{|c|}{ 95\% wald confidence Internal } & \multicolumn{3}{|l|}{ hypothesis test } \\
\hline & & & Lower & Upper & wald chi-square & df & $p$-value \\
\hline intercept & 5169.088 & 2572.454 & 127.170 & $10,211.006$ & 4.038 & 1 & 0.044 \\
\hline [region = 1] & 1289.574 & 979.440 & -630.093 & 3209.241 & 1.734 & 1 & 0.188 \\
\hline [region = 2] & 1700.035 & 1349.644 & -945.219 & 4345.288 & 1.587 & 1 & 0.208 \\
\hline [region = 3] & $0 b$ & & & & & & \\
\hline [gender $=1]$ & -544.542 & 1937.713 & -4342.389 & 3253.305 & 0.079 & 1 & 0.779 \\
\hline [gender = 2] & $0 b$ & & & & & & \\
\hline age & -400.917651 & 707.808 & -1788.195 & 986.360 & 0.321 & 1 & 0.571 \\
\hline [types of BMI = 1] & 360.977 & 1220.132 & -2030.437 & 2752.391 & 0.088 & 1 & 0.767 \\
\hline [types of BMII = 2] & $0 b$ & & & & & & \\
\hline [grades of medical institution $=0$ ] & 159.418 & 759.276 & -1328.734 & 1647.571 & 0.044 & 1 & 0.834 \\
\hline [grades of medica linstitution = 1] & 9223.120 & \#\#\#\#\#\# & $-13,906.490$ & $32,352.730$ & 0.611 & 1 & 0.434 \\
\hline [grades of medica linstitution = 2] & 1986.024 & 1177.259 & -321.361 & 4293.410 & 2.846 & 1 & 0.092 \\
\hline [grades of medical institution = 3] & Ob & & & & & & \\
\hline [types of medical service $=1$ ] & -5085.887 & 772.286 & -6599.540 & -3572.233 & 43.369 & 1 & 0.000 \\
\hline [types of medical service = 2] & Ob & & & & & & \\
\hline reimbursement ratio & 27.518 & 10.756 & 6.437 & 48.600 & 6.546 & 1 & 0.011 \\
\hline scale & $69,869,737.205$ & & & & & & \\
\hline
\end{tabular}

progress, variation in medical practice, and health system characteristics, reflect the consumption of health resources and services by patients [22-24]. A previous study revealed that the median total treatment costs of patients with 8 certain rare diseases in 2013, 2014 and
2015 were $¥ 6548$, ¥3752, ¥5378, respectively [25]. In our study, the median of the annual health expenditure of patients with hemophilia in 2014 was $¥ 7167$, which was significantly higher than that in the previous study. The annual health expenditure for patients with hemophilia

Table 3 The generalised estimating equation analysis of reimbursement ratio

\begin{tabular}{|c|c|c|c|c|c|c|c|}
\hline \multirow[t]{2}{*}{ Parameter } & \multirow[t]{2}{*}{ B } & \multirow[t]{2}{*}{ Std.Error } & \multicolumn{2}{|c|}{ 95\% wald confidence Internal } & \multicolumn{3}{|l|}{ hypothesis test } \\
\hline & & & Lower & Upper & wald chi-square & $\mathrm{df}$ & $p$-value \\
\hline intercept & 11.876 & 8.858 & -5.486 & 29.238 & 1.797 & 1 & 0.180 \\
\hline [region = 1] & 21.074 & 3.556 & 14.104 & 28.043 & 35.124 & 1 & 0.000 \\
\hline [region = 2] & 10.397 & 3.511 & 3.516 & 17.278 & 8.770 & 1 & 0.003 \\
\hline [region = 3] & $0 \mathrm{a}$ & & & & & & \\
\hline [gender = 1] & 38.345 & 7.054 & 24.519 & 52.170 & 29.549 & 1 & 0.000 \\
\hline [gender = 2] & Oa & & & & & & \\
\hline age & -2.587 & 2.046 & -6.598 & 1.424 & 1.598 & 1 & 0.206 \\
\hline [types of BMI = 1] & 15.129 & 3.252 & 8.756 & 21.503 & 21.649 & 1 & 0.000 \\
\hline [types of BMII = 2] & Oa & & & & & & \\
\hline [grades of medical institution =0] & 7.901 & 3.409 & 1.219 & 14.583 & 5.371 & 1 & 0.020 \\
\hline [grades of medica linstitution = 1] & 15.348 & 3.952 & 7.602 & 23.093 & 15.083 & 1 & 0.000 \\
\hline [grades of medica linstitution = 2] & -0.060 & 3.004 & -5.948 & 5.828 & 0.000 & 1 & 0.984 \\
\hline [grades of medical institution $=3$ ] & Oa & & & & & & \\
\hline [types of medical service $=1$ ] & -3.431 & 2.951 & -9.214 & 2.353 & 1.352 & 1 & 0.245 \\
\hline [types of medical service = 2] & Oa & & & & & & \\
\hline medical expenses & 0.000 & 0.000 & 0.000 & 0.001 & 2.844 & 1 & 0.092 \\
\hline scale & 687.056 & & & & & & \\
\hline
\end{tabular}


in 2014 to 2015 had median of $¥ 3522$ and $¥ 4197$, which were lower than the previous study. These values differed probably because the drugs used to treat hemophilia were listed in basic medical insurance reimbursement schemes. These drugs purchased using basic medical insurance funds are procured through bidding and negotiation, and it can significantly reduce drugs' prices [26].

In this study, it was observed that the more frequent hospital admission and the longer the hospital stays, the higher the medical expenditure of patients with hemophilia. This also meant these that patients suffered from severe hemophilia and endured high annual treatment cost, which was consistent with the previous results [27-29].

RR was significant positive in 50th and 70th quantiles possibly because of the difference in health service utilization among different insurance schemes. Previous studies indicated that patients covered by different health schemes have different medical expenses in China. Patients covered by UEBMI with a high RR use more health services, which entail additional treatment costs. The cost of hospitalization, length of stay and frequency of hospitalization of patients in rural areas were lower than those of patients in urban areas [30,31].

The types of medical service were significant negative in the 50th quantile. The common treatment of patients with hemophilia was coagulation factor injection, which was mainly provided by the outpatient department. Patients that repeatedly made use of the outpatient services in a year also had a considerable amount of medical cost [32]. In our study, the annual treatment cost was not statistically different between adults and children. This result was consistent with the hemophilia-associated cost in Portugal [33].

The limitations of this study should also be noted. Firstly, patients with hemophilia covered by the NRCMS were excluded because our data did not provide relevant information. Secondly, this study did not pay attention to the socio-economic factors, health needs and service utilization of patients with hemophilia because relevant data were not available.

\section{Conclusion}

Hemophilia, which is a costly but treatable rare disease, is included in the scope of basic medical insurance reimbursement in China. The medical expenditure of patients with hemophilia was lower than that of other common rare diseases that are not included in the scope of basic medical insurance reimbursement. The medical expenditure of patients with hemophilia was mainly influenced by disease severity, and partly affected by the RR. Further studies are required to focus on the effects of basic medical insurance on the medical expenditures of patients with hemophilia, design a reasonable reimbursement policy that may reduce treatment costs and improve the efficiency of health services.

\section{Abbreviations}

UEBMI: Urban employee basic medical insurance; NRCMS: New rural cooperative medical system; URBMI: Urban residence basic medical insurance

\section{Acknowledgements}

The authors thank the China Health Insurance Research Association for their willingness to provide us with the data.

\section{Authors' contributions}

Pengqian Fang and Rui Min contributed to the data acquisition and provided statistical analysis support; Guangwen Gong analyzed the data and wrote the paper. Yingchun Chen revised the paper. All authors supplied critical revisions to the manuscript and gave final approval of the version to be published.

\section{Funding}

This work was supported by the National Social Science Foundation of China (No. 15ZDC037) and the National Natural Science Foundation of China (No. 71333005). The funders had no role in the study design, data collection and analysis, decision to publish or preparation of the manuscript.

\section{Availability of data and materials}

The data used in this study were obtained with permission from the China Healthcare Insurance Research Association, information related to patients' privacy was not extracted. The corresponding author has full access to all the data used in the study.

\section{Ethics approval and consent to participate}

This study did not involve any primary data collection and no patients' privacy data is included.

\section{Consent for publication}

Not applicable.

\section{Competing interests}

The authors hold no financial interests in the sponsoring organization. The results described here do not contain any product specific names or literature from the sponsoring company. The authors stated that they have no interests, which might be perceived as posing a conflict or bias.

Received: 23 September 2019 Accepted: 27 May 2020

Published online: 05 June 2020

\section{References}

1. Siddiqi AEA, Ebrahim SH, Soucie JM, Parker CS, Atrash HK. Burden of disease resulting from hemophilia in the US. Am J Prev Med. 2010;38(4):S482-8.

2. Kodra Y, Cavazza M, Grosse Schieppati A, et al. The social burden and quality of life of patients with haemophilia in Italy. Blood Transfus. 2014;12 Suppl 3(Suppl 3):S56775. https://doi.org/10.2450/2014.0042-14s.

3. China Daily. Hemophilia network set up in China. 2012. http://www.chinadaily.com. cn/china/2010-01/14/content_9317729.htm Accessed 14 Jan 2010.

4. Poon MC, Luke KH. Hemophilia care in China: achievements of a decade of World Federation of Hemophilia treatment Centre twinning activities. Hemophilia. 2008;14:879-88.

5. Zhang L, Chen G, Brooks-Rooney C, et al. Comprehensive evaluation of the diseases burden associated with hemophilia a in China. Value Health. 2016; 19:585-6.

6. Qu Y, Nie X, Yang Z, et al. The prevalence of hemophilia in mainland China: a systematic review and meta-analysis. Southeast Asian J Trop Med Public Health. 2014 Mar:45(2):455-66.

7. Li JF, Zeng XH, Huang $Q$, et al. Investigation on medical insurance of hemophilia patients in Guangdong province. Health Econ Res. 2010;12:37-9.

8. Tang L, Zhang JS, Wu RH. Assessment of the quality of life and the family burden of diseases in moderate or severe hemophilia children with joint complications. Chinese J Thrombosis Hemostasis. 2014;1:8-12. 
9. Qu YJ, Yin H, Pang YJ, et al. Treatment status and economic burden of people with hemophilia in mainland China: a systematic review. Chin J Evid Based Med. 2013. https://doi.org/10.7507/1672-2531.20130032.

10. Yu H. Universal health insurance coverage for 1.3 billion people: What accounts for China's success? Health Policy. 2015;9:1145-1152.12.

11. Fleisher B, Li H, Zhao MQ. Human capital, economic growth, and regional inequality in China. J Dev Econ. 2010;2:215-31.

12. Fan $S$, Kanbur $R$, Zhang $X$. China's regional disparities: experience and policy. Rev Dev Finance. 2011;1:47-56.

13. World Health Report (2010) Background Paper, No 37. Health insurance systems in China: A briefing note. https:/www.who.int/healthsystems/ topics/financing/healthreport/37ChinaB_YFINAL.pdf.

14. Sun Y, Gregersen H, Yuan W. Chinese health care system and clinical epidemiology. Clin Epidemiol Vol. 2017;9:167-78.

15. Zhu K, Zhang L, Yuan S, et al. Health financing and integration of urban and rural residents' basic medical insurance systems in China. Int J Equity Health. 2017;16(1):194

16. Su M, Zhou Z, Si Y, et al. Comparing the effects of China's three basic health insurance schemes on the equity of health-related quality of life: using the method of coarsened exact matching. Health Qual Life Outcomes. 2018;16:41.

17. Hu J, Mossialos E. Pharmaceutical pricing and reimbursement in China: When the whole is less than the sum of its parts. Health Policy. 2016. https://doi.org/10.1016/j.healthpol.2016.03.014.

18. The ministry of labor and social security of the People's Republic of China. Basic medical insurance, industrial injury insurance drug list (2004 edition). Peking: China labor press; 2004. p. 48.

19. Ministry of human resources and social security of the People's Republic of China. The ministry of labor and social security of the People's Republic of China. Basic medical insurance, industrial injury insurance drug list (2009 edition). Peking: China labor press; 2009. p. 52.

20. Ministry of human resources and social security of the People's Republic of China: The ministry of human resources and social security issued a list of medicines for national basic medical insurance, work injury insurance and maternity insurance (2017edition). http://www.gov.cn/xinwen/2017-02/23/ content_5170392.htm. Accessed 23 Feb 2017.

21. Ministry of human resources and social security of the People's Republic of China: The ministry of human resources and social security issued a notice on the inclusion of 36 drugs in the category b of the state basic medical insurance, work injury insurance and maternity insurance. http://www mohrss.gov.cn/SYrlzyhshbzb/shehuibaozhang/zcwj/yiliao/201707/t2017071 8_274153.html. Accessed 23 July 2017.

22. Zhao J, Zhong H. Medical expenditure in urban China: a quantile regression analysis. Int J Health Econ Manag. 2015;15:1-20 Validated CrossRef.

23. WHO: The determinants of health expenditure. https://www.who.int/health financing/documents/report_en_11_deter-he.pdf. Accessed Dec 2011.

24. Gerdtham UG, Jönsson B, Macfarlan M, et al. The Determinants of Health Expenditure in the OECD Countries: A Pooled data Analysis. Health, the Medical Profession, and Regulation: Springer US; 1998. https://doi.org/10. 1007/978-1-4615-5681-7_6.

25. Min $R$, Zhang $X$, Fang $P$, et al. Health service security of patients with 8 certain rare diseases: evidence from China's national system for health service utilization of patients with healthcare insurance. Orphanet J Rare Dis. 2019. https://doi.org/10.1186/s13023-019-1165-7.

26. China Daily: Drug price cuts a good remedy. Drug price cuts a good remedy - Chinadaily.com.cn.http://usa.chinadaily.com.cn/a/201812/12/WS5 c107c0ca310eff3032908f6.htm.IAccessed 8 Dec 2018.

27. Chen SL. Economic costs of hemophilia and the impact of prophylactic treatment on patient management. Am J Manag Care. 2016;22:S126-33.

28. Armstrong EP, Malone DC, Krishnan S, et al. Costs and utilization of hemophilia a and B patients with and without inhibitors. J Med Econ. 2014;11:798-802.

29. Guh S, Grosse SD, McAllister S, et al. Health care expenditures for Medicaidcovered males with haemophilia in the United States, 2008. Haemophilia. 2012;18(2):276-83. https://doi.org/10.1111/j.1365-2516.2011.02713.x.

30. Chou WL, Wang Z. Regional inequality in China's health care expenditures. Health Econ. 2010;18:S137-46.

31. Pan $Y$, Chen $S$, Chen $M$, et al. Disparity in reimbursement for tuberculosis care among different health insurance schemes: evidence from three counties in Central China. Infect Dis Poverty. 2016;5:46-54.

32. Dong $\mathrm{ZH}$, Chen BB, Li ZQ. Medical insurance and management analysis of hemophilia based on the experience of Shenzhen. China Health Insurance. 2018;1:32-5.
33. Patrícia Rocha, Manuela Carvalho, Manuela Lopes, Fernando Araújo. Costs and utilization of treatment in patients with hemophilia. BMC Health Services Res. 2015;15(1).

\section{Publisher's Note}

Springer Nature remains neutral with regard to jurisdictional claims in published maps and institutional affiliations.
Ready to submit your research? Choose BMC and benefit from:

- fast, convenient online submission

- thorough peer review by experienced researchers in your field

- rapid publication on acceptance

- support for research data, including large and complex data types

- gold Open Access which fosters wider collaboration and increased citations

- maximum visibility for your research: over $100 \mathrm{M}$ website views per year

At BMC, research is always in progress.

Learn more biomedcentral.com/submissions 